\title{
AVALIAÇÃO DO USO DE CONCHA DE MARISCO COMO ADSORVENTE PARA REMOÇÃO DO CORANTE REATIVO AZUL TURQUESA QG
}

\author{
N. E. S. SANTOS ${ }^{1}$, T. E. P SILVA ${ }^{2}$, J. J. SILVA ${ }^{2}$ e M. M. M. B. DUARTE ${ }^{2}$ \\ ${ }^{1}$ Universidade Federal de Pernambuco, Departamento de Engenharia Química. \\ ${ }^{2}$ Universidade Federal de Pernambuco, Departamento de Engenharia Química. \\ E-mail para contato: nathalieelizabelle@yahoo.com.br
}

\begin{abstract}
RESUMO - Os efluentes têxteis possuem coloração, devendo ser tratados antes de seu descarte. Um processo utilizado para remoção de corantes de efluentes é a adsorção. Este trabalho avaliou a eficiência de conchas de mariscos como adsorvente para remoção do corante Reativo Azul Turquesa QG. Foi determinado o ponto de carga zero (pHpcz), a influência do pH inicial da solução e da concentração do adsorvente (CA). Foi realizado um planejamento fatorial $2^{3}(\mathrm{PF})$ para avaliar a influência das variáveis CA, granulometria (G) e velocidade de agitação (VA) sobre o sistema adsortivo. A capacidade adsortiva $q$ foi utilizada para avaliação dos efeitos. O pHpcz foi de 8,7 , o que favorece a adsorção de corantes aniônicos. O maior $q$ foi obtido para $\mathrm{pH} 2$ e a CA de $8 \mathrm{~g} . \mathrm{L}^{-1}$, interseção das curvas $q$ e \% de remoção, foi adotada como ponto central do PF. A condição de trabalho que forneceu o maior $q$ no PF foi 4 g. $\mathrm{L}^{-1}, \mathrm{G}$ de $0,150-0,212 \mathrm{~mm}$ e sem agitação. Os resultados demonstram o potencial técnico da concha de marisco como adsorvente no caso em estudo.
\end{abstract}

\section{INTRODUÇÃO}

A água utilizada nas indústrias têxteis é um meio de transporte para os produtos químicos que entram no processo, e em seguida para a remoção dos produtos indesejáveis (ou excedentes) à geração do produto final. Sua carga poluidora nos efluentes aquosos corresponde aos produtos adicionados para facilitar os processos de fiação e tecelagem, aos produtos químicos auxiliares e aos corantes eliminados durante as etapas de acabamento (CAMELO, 2011). O acabamento e a tinturaria constituem as etapas do processo produtivo com cargas poluidoras mais elevadas.

A presença de corantes têxteis em águas residuais industriais provoca graves consequências ao meio ambiente, pois a maioria são compostos tóxicos e altamente resistentes à degradação (GONG et al., 2007). Afetam a estética, a transparência da água e a solubilidade de gases nos corpos receptores, e reduzem a capacidade de aeração dos corpos hídricos em função da penetração de luz solar afetando os processos de fotossíntese (PIVA et al., 2011). Estima-se que cerca de 10 a $20 \%$ dos corantes permanecem em águas residuais (LI et al., 2009). 
Os corantes reativos possuem caráter aniônicos como, por exemplo, o corante Turquesa Reativo QG (SCHIMMEL, 2008). A classe dos corantes reativos também possui alta solubilidade em água e grupos reativos adequados que formam ligações covalentes entre o corante e a fibra, sendo a mais usada entre as diferentes classes de corantes (MOSCOFIAN, 2009).

As indústrias têxteis têm grande dificuldade em remover os corantes de suas águas residuárias. Esses efluentes, em sua maioria, são os mais complexos e problemáticos a serem tratados, pois apresentam elevadas demandas químicas e bioquímicas de oxigênio, grandes quantidades de sólidos suspensos e coloração bastante acentuada (AKSU, 2005).

Os principais métodos utilizados na remoção de corantes nos efluentes são a adsorção, floculação, oxidação, eletrólise e métodos biológicos (BORBA et al., 2012). Os processos adsortivos se destacam por sua simplicidade de projeto e operação, insensibilidade a substâncias tóxicas, facilidade de regeneração e baixo custo, além de evitar a utilização de solventes tóxicos (SOTO et al., 2011).

Diversos materiais adsorventes vêm sendo estudados, tais como: cascas de crustáceos (TABORDA, 2009), bambu (HSING; PAULA, 2011), caroços de jaca (FOO; HAMEED, 2012), fibras de algodão (SUN et al., 2012), casca de laranja (Nascimento, et al., 2014).

As vantagens de se utilizar biossorvente no lugar de adsorventes convencionais estão notadamente na relação custo-benefício inerente a essa tecnologia (CALFA; TOREM, 2007). As conchas de marisco são resíduos oriundos da maricultura, que gera diversos problemas ambientais devido à má destinação dos restos da produção, proporcionando ambientes adequados para o desenvolvimento de vetores de doenças, degradando a paisagem local, prejudicando o turismo e o comércio da região (LIMA et al., 2000; PEREIRA et al., 2013).

Diante do exposto, o presente trabalho teve por objetivo avaliar a eficiência de conchas de mariscos, resíduo oriundo das atividades das marisqueiras, como adsorvente para remoção do corante Reativo Azul Turquesa QG de soluções aquosas.

\section{METODOLOGIA}

Neste trabalho, para ajuste de $\mathrm{pH}$ foram utilizados soluções de ácido clorídrico $(\mathrm{HCl}, 0,1$ mol. $\mathrm{L}^{-1}$ ) ou hidróxido de sódio ( $\mathrm{NaOH}, 0,1$ mol. $\mathrm{L}^{-1}$ ) medidos em pHmetro (marca Hanna). Os experimentos de adsorção foram realizados em banho finito ao final de cada ensaio, os teores do corante foram quantificados antes e após a execução dos experimentos pela técnica Espectrometria UV-VIS. Foram realizados ensaios em branco, seguindo-se o mesmo procedimento das amostras. A quantidade adsorvida por massa de adsorvente no equilíbrio (capacidade adsortiva $q_{o}$ ) foi calculada utilizando a Equação 1:

$$
q=\frac{\left(c_{0}-c_{f}\right) V}{m}
$$


Sendo $q$ a quantidade do adsorbato em $\mathrm{mg}$ de adsorvato.g ${ }^{-1}$ de adsorvente, $C_{o}$ a concentração inicial $\left(\mathrm{mg} . \mathrm{L}^{-1}\right), C_{f}$ a concentração no equilíbrio (mg. $\left.\mathrm{L}^{-1}\right), V$ o volume da solução (L) e $S$ a massa de adsorvente (g).

\subsection{Preparação do material adsorvente}

As conchas de marisco foram coletadas nas margens do canal de Santa Cruz, Igarassu-PE, localizado a uma latitude 07 $50^{\prime} 03^{\prime \prime}$ sul e a uma longitude $34^{\circ} 54^{\prime} 23^{\prime \prime}$ oeste, estando a uma altitude de 19 metros. A coleta foi realizada em novembro de 2013, e o adsorvente preparado seguindo as etapas: Lavagem em água corrente e água destilada, e em seguida foi seco à temperatura ambiente $\left(30 \pm 5^{\circ} \mathrm{C}\right)$. As conchas tiveram seu tamanho reduzido por trituração manual, foi realizada uma nova lavagem após a moagem, com água corrente e água destilada e secas $\left(30 \pm 5^{\circ} \mathrm{C}\right)$.

A classificação do material foi realizada utilizando uma serie de peneiras Tyler nas de granulometrias < 0,090; 0,090-0,150 e 0,150-0,250mm.

\subsection{Determinação do ponto de carga zero}

$\mathrm{O}$ valor do ponto de carga zero foi estimado a partir do gráfico de $\left(\mathrm{pH}_{\text {final }}-\mathrm{pH}_{\text {inicial }}\right)$ versus $\mathrm{pH}_{\text {inicial. }}$ Os ensaios foram realizados utilizando $0,1 \mathrm{~g}$ do adsorvente em $25 \mathrm{~mL}$ de água variando o $\mathrm{pH}$ de 2 a 10. As soluções permaneceram em agitação de $300 \mathrm{rpm}$ por 24 horas, em seguida filtradas e o $\mathrm{pH}$ medido.

\subsection{Efeito do $\mathrm{pH}$ inicial da solução do corante}

$\mathrm{O}$ efeito do $\mathrm{pH}$ inicial da solução do corante foi avaliado numa faixa de $\mathrm{pH}$ de 2 a 10 . O adsorvente $(0,1 \mathrm{~g})$ foi adicionado a $25 \mathrm{ml}$ da solução do corante nos respectivos $\mathrm{pH}$ permanecendo sob agitação $300 \mathrm{rpm}$ por $6 \mathrm{~h}$.

\subsection{Influência da concentração do adsorvente}

Para avaliar a influência da concentração foram realizados ensaios de adsorção com as massas de 0,$1 ; 0,2 ; 0,4 ; 0,6 ; 0,8 ; 1,0 \mathrm{~g}$ do adsorvente em $25 \mathrm{~mL}$ da solução. As soluções permaneceram em agitação de $300 \mathrm{rmp}$ por $6 \mathrm{~h}$.

\subsection{Definição das condições de trabalho}

Foi realizado planejamento fatorial $2^{3}$ com ponto central em triplicata para avaliar as influências das variáveis concentração do adsorvente, granulometria do adsorvente e velocidade de agitação sobre os processos adsortivos. A resposta utilizada para determinar a eficiência do processo foi a capacidade adsortiva $\left(q, \mathrm{mg}_{\mathrm{g}} \mathrm{g}^{-1}\right)$. Os cálculos dos efeitos dos fatores e as interações entre eles com os seus respectivos erros padrão foram calculados segundo Barros Neto, Scarminio e Bruns (2007), com auxílio do programa Statistica for Windows 6.0. 


\section{RESULTADOS E DISCUSSÃO}

\subsection{Determinação do ponto de carga zero}

Observa-se na Figura 1 que a intercessão com o eixo horizontal foi no $\mathrm{pH} 8,7$ que corresponde ao $\mathrm{pH}$ do ponto de carga zero $\left(\mathrm{pH}_{\mathrm{pcz}}\right)$. Isto indica que em $\mathrm{pH}$ inferiores a esse valor o adsorvente possui carga superficial positiva favorecendo a adsorção de ânions, como o corante em estudo.

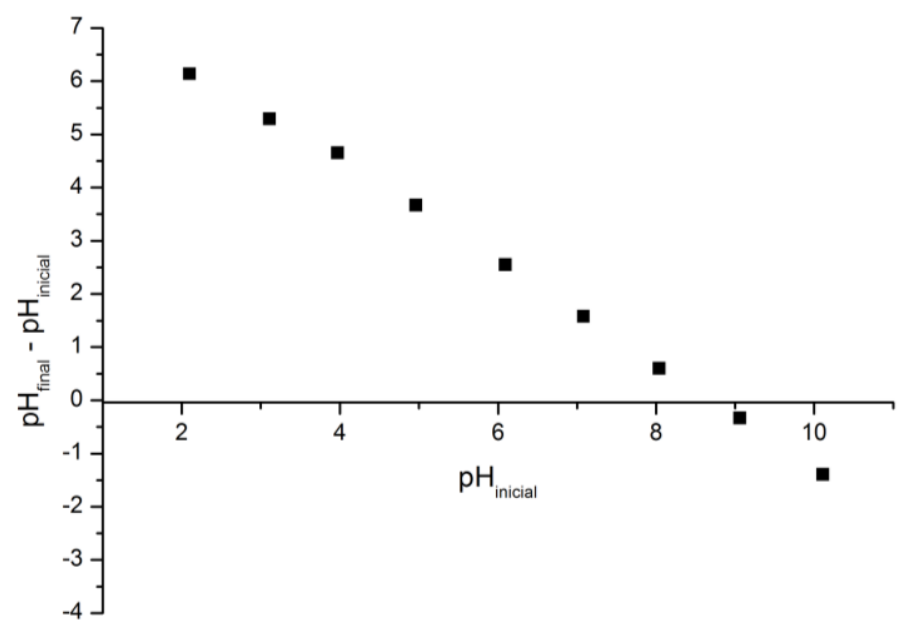

Figura 1 - Ponto de carga zero para a concha de marisco.

$\mathrm{O}$ valor do $\mathrm{pH}_{\mathrm{pcz}} 8,7$, sugere que o bioadsorvente possui uma superfície alcalina, sendo coerente com a afirmação de Lee e Davis (2001), que verificaram que os sítios de coordenação da superfície de bioadsorventes consistem principalmente de grupos hidroxila com contribuição de grupos funcionais carboxílicos e amina. Rimar (2013) encontrou um valor de $\mathrm{pH}_{\mathrm{pcz}}$ para conchas de marisco de 8,82, confirmando ser um bom adsorvente para materiais de carga negativa.

\subsection{Efeito do pH inicial da solução do corante}

A solução do corante com $\mathrm{pH}$ inicial 2 foi a que forneceu maior capacidade adsortiva, conforme pode ser visto na Figura 2. Este valor de $\mathrm{pH}$ foi adotado para todos os procedimentos de adsorção. 


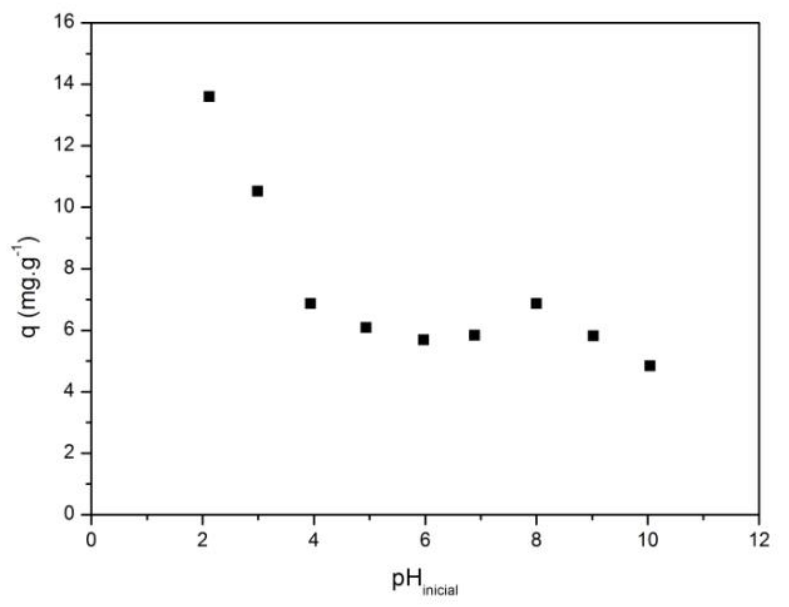

Figura 2 - Efeito do pH inicial da solução do corante.

Segundo Fiorentin et al., (2010) os corantes reativos que possuem grupos vinil-sulfona, em meio ácido, podem sofrer desprotonação da molécula do corante no seio da solução, resultando em uma molécula polar ( $\mathrm{R}-\mathrm{SO}_{3}$-) com uma densidade de carga negativa elevada. A diminuição do $\mathrm{pH}$ carrega positivamente os sítios, aumentando a carga superficial positiva dos adsorventes. Portanto, em valor de baixo $\mathrm{pH}$, a repulsão eletrostática entre os sítios do adsorvente e os íons negativos da solução do corante é reduzida, explicando assim, o aumento da capacidade de adsorção em pH 2.

\subsection{Influência da concentração do adsorvente}

O efeito da variação da concentração do adsorvente no sistema adsortivo corante/concha está apresentado na Figura 3.

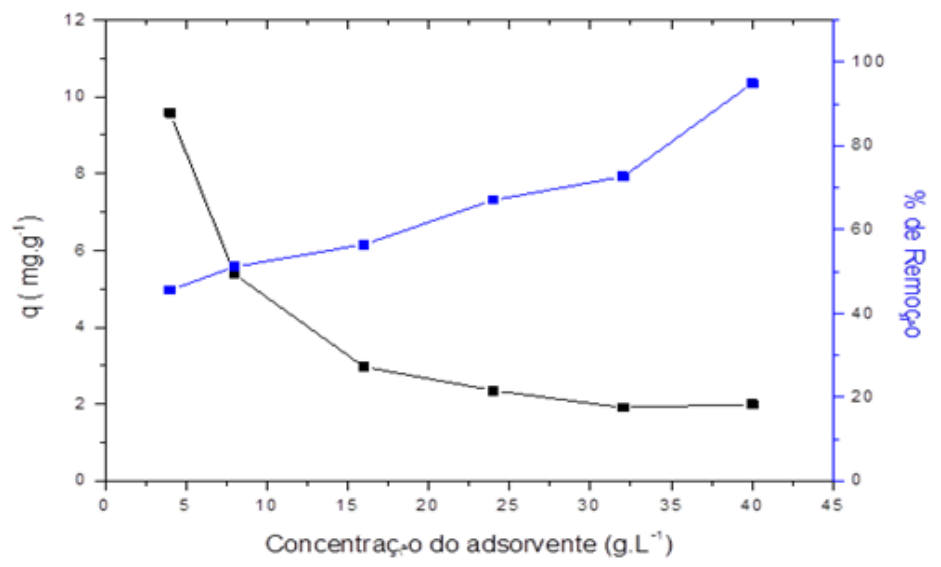

Figura 3 - Influência da concentração do adsorvente no sistema adsortivo corante/concha. 
Pode ser observada na Figura 3, que a quantidade de corante adsorvida por unidade de massa do adsorvente diminuiu de $9,6 \mathrm{mg}^{-\mathrm{g}^{-1}}$ para $2,0 \mathrm{mg} \cdot \mathrm{g}^{-1} \mathrm{com}$ o aumento da concentração da concha de marisco, e o aumento do \% de remoção do corante azul-turquesa de 45,5 para 94,8\%. Esse incremento provavelmente ocorre devido a uma maior disponibilidade da área superficial e consequentemente do número de sítios ativos.

A intercessão das duas curvas ocorreu no valor da concentração do adsorvente 8 g. $\mathrm{L}^{-1}$, que foi utilizado como ponto central do planejamento fatorial visando melhorar a relação da capacidade adsortiva e o \% de remoção.

\subsection{Definição das condições de trabalho}

Os efeitos principais e suas interações de 2 e 3 fatores, foram calculados em um nível de 95\% de confiança utilizando-se o software STATÍSTICA, versão 6.0. Foram considerados significativos os efeitos cujo valor absoluto excederem a 0,39 .

O efeito principal Velocidade de Agitação e o efeito de interação Concentração do Adsorvente vs. Velocidade de Agitação não foram estatisticamente significativos a um nível de 95\% de confiança. Podendo ser melhor visualizados através da carta de Pareto (Figura 4).

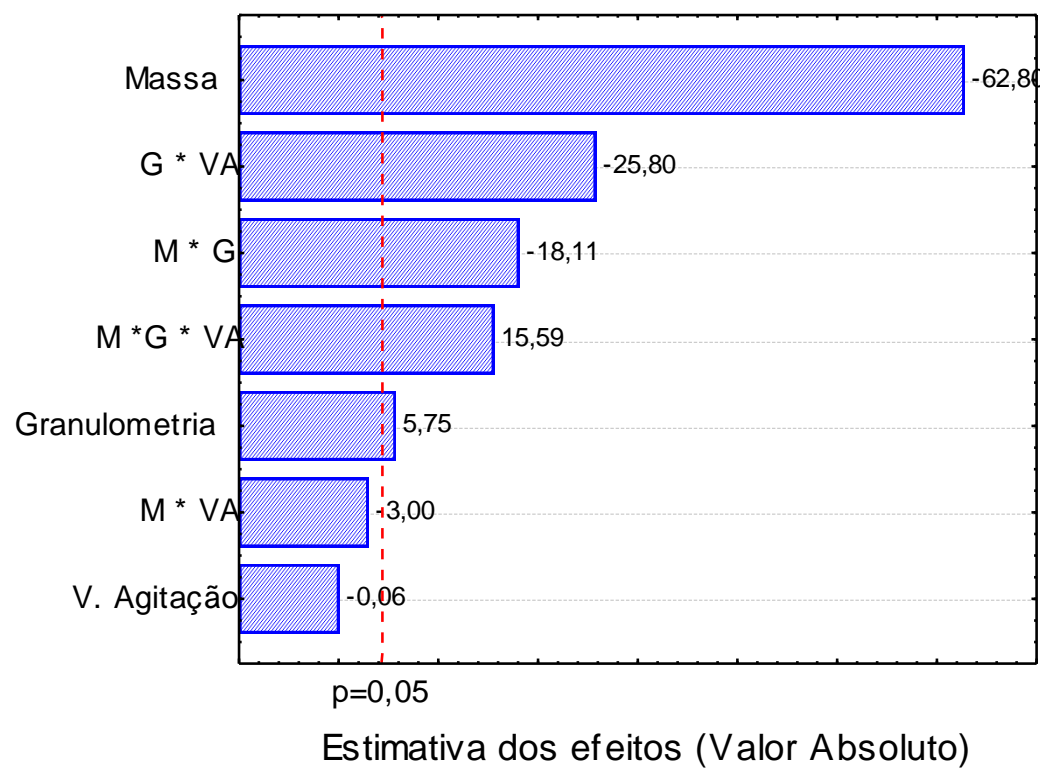

Figura 4 - Carta de Pareto dos efeitos calculados da concha de marisco (erro puro de 0,017).

As superfícies de respostas referentes as interações de dois fatores estatisticamente significativo estão apresentados na Figuras 5. 

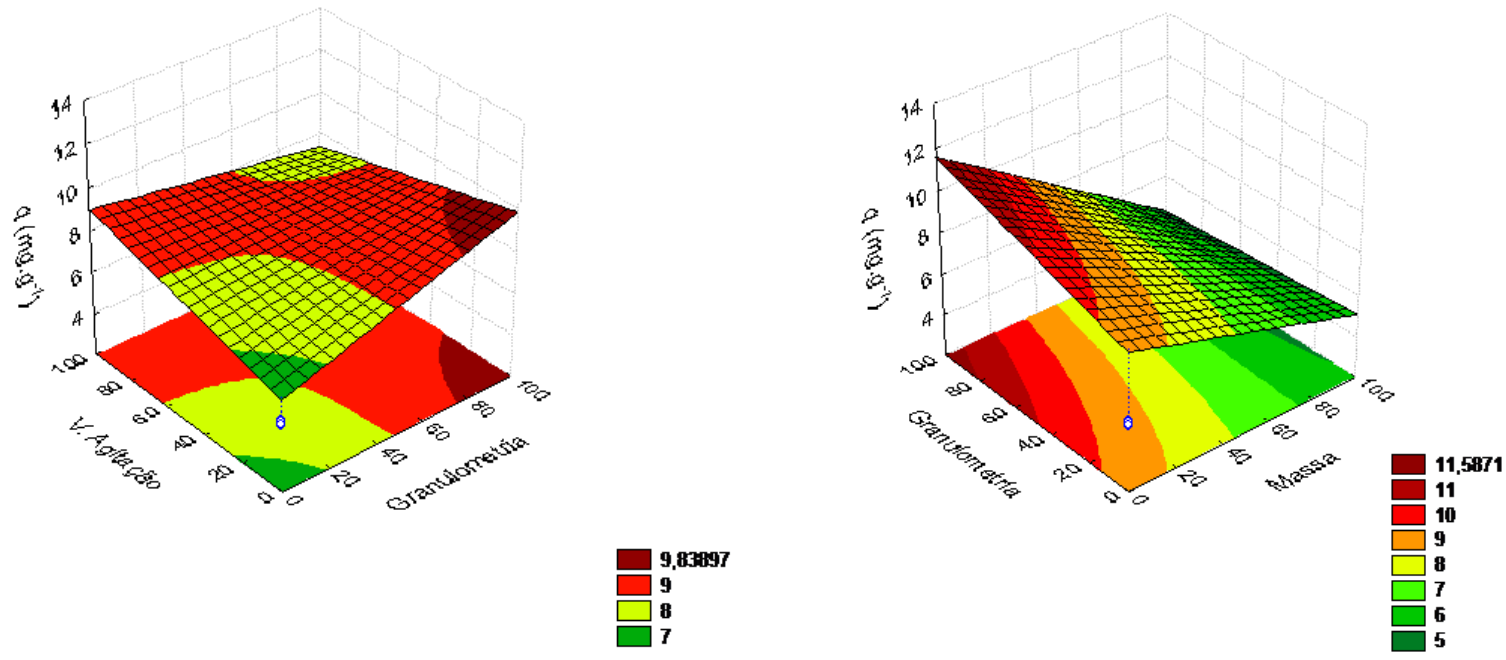

Figura 5 - Superfície de resposta. A - Granulometria vs. Velocidade de Agitação e B Concentração do Adsorvente vs. Granulometria.

A maior quantidade de corante adsorvida por massa de adsorvente $\left(13 \mathrm{mg} . \mathrm{g}^{-1}\right)$ ocorreu no nível 4 g.L $\mathrm{L}^{-1}$, granulometria de 0,150 - 0,212 e sem agitação.

\section{CONCLUSÃO}

O adsorvente estudado apresenta-se como alternativa técnica viável para remoção do corante Reativo Azul Turquesa QG em solução aquosa. Podendo assim compatibilizar as questões ambientais, usando um resíduo para tratar outro.

\section{REFERÊNCIAS}

AKSU, Z. Aplication of biosorption for the removal of organic pollutants: a review. ProcessBiochemistry, v. 40, n. (3-4), p. 997-1026, 2005.

BARROS NETO, B.; SCARMINIO, I. S.; BRUNS, R. E., Como Fazer Experimentos: pesquisa e desenvolvimento na ciência e na indústria. Ed. Unicamp. Campinas-SP, 480 p. 2007.

BORBA, C. E.; MÓDENES, A. N.; EPINOZA-QUIÑONES, F. R.; BORBA, F. H.; BASSI, A. F.; RIBEIRO, C. Estudo da cinética e do equilíbrio de adsorção dos corantes azul turquesa QG e amarelo reativo 3R em carvão ativado. Engevista, v. 14, n. 2, p. 135-142, 2012.

CALFA, B. A.; TOREM, M. L. Biorreagentes - aplicações na remoção de metais pesados contido em efluentes líquidos por biossorção/bioflotação. Revista Escola de Minas, v. 60, n. 3, p. 537-542, 2007.

CAMELO, CARLOS A. M. G. Reutilização de águas de tingimento através de nanofiltração. 130f. 2011. Dissertação de mestrado. Porto, Portugal: Instituto Superior de Engenharia do Porto, 2011.

FIORENTIN, L.; TREVISAN, I; ROSIN, L; PEREIRA, N. Remoção de resíduos de efluentes têxteis utilizando processo de adsorção contínua com bagaço de laranja como adsorvente. In: VIII Congresso Brasileiro de Engenharia Química. Arquivo digital em formato PDF. Uberlândia. 2010. 


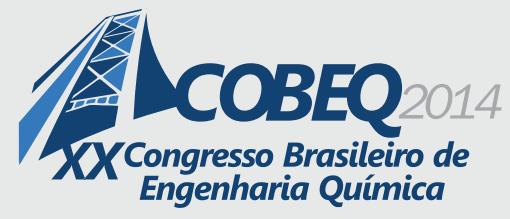

19 a 22 de outubro de 2014

Florianópolis/SC

FOO, K. Y.; HAMEED, B. H. Potential of jackfruit peel as precursor for activated carbon prepared by microwave induced $\mathrm{NaOH}$ activation. Bioresource Technology, v. 112, p. 143-150, 2012.

GONG, R.; ZHANG, X.; LIU, H.; SUN, Y.; LIU, B. Uptake of cationic dyes from aqueous solution by biosorption on to granular kohlrabi peel. Bioresource Technology,v.98, n. 6, p. 1319-1323, 2007.

HSING, T.Y.; PAULA, N.F. Produção e caracterização de carvão ativado de quatro espécies de bambu. IV Semana de Tecnologia do Curso de Biocombustíveis da Faculdade de Tecnologia de Jaboticabal. Ciência\&Tecnologia: FATEC-JB, Jaboticabal 3, 2011.

LEE, S. M.; DAVIS, A. P. Removal of $\mathrm{Cu}$ (II) and Cd (II) from aqueous solution by seafood processing wast sludge. Water Research, v. 35, n. 2, p. 534-540, 2001.

LI, Q. ; YUE, Q. Y.; SU, Y.; GAO, B. Y., LI, J. Two-step kinetic study on the adsorption and desorption of reactive dyes at cationic polymer/bentonite. Journal of Hazardous Materials, v. 165, n. (1-3), p. 1170$1178,2009$.

LIMA, H. C.; BARBOSA, J. M.; CORREIA, D. S., Extração de mariscos por moradores da comunidade de Beira-mar 2, Igarassu-PE. Mangueizais, Editora Universitária da UFPE,p. 108-109, 2000.

MOSCOFIAN, Andrea S. de O. Filossilicatos de magnésio e sílicas mesoporosas organofuncionalizados para o uso na remoção de corantes industriais. 122f. 2009. Tese de Doutorado. Campinas, SP: Universidade Estadual de Campinas: UNICAMP, 2009.

NASCIMENTO, G. E.; DUARTE, M. M. M. B.; CAMPOS, N. F.; ROCHA, O. R. S.; SILVA, V. L. Adsorption of azo dyes using peanut hull and orange peel: a comparative study. Environmental Technology. Mortimer House, 37-41 Mortimer Street, London W1T 3JH, UK 2014.

PEREIRA, P. M.;LEMOS, V. P.; RODRIGUES, E.; FAIAL, K. C. F. Adsorção de molibdato em minerais de argilas naturais e modificadas com ácido sulfúrico, ácido húmico e uréia. Cerâmica, v. 59, n. 349, p. 170-180, 2013.

PIVA, J. A. L.; SANTOS, O.; ANDRADE, C. M. G. Determinação e análise de isotermas de adsorção do corante azul 5G em leito fixo de carvão ativada. ActaScientiarum.Technology, v. 33, n. 4, p. 435-438, 2011.

RIMAR, K. K. P. P. Avaliação da capacidade da concha do marisco Anomalocardia brasiliana em adsorver ferro em amostras de águas subterrâneas. 96 f. Tese de doutorado (Doutorado em Química). João Pessoa, PB: Universidade Federal da Paraíba, 2013.

SCHIMMEL, D. Adsorção dos corantes reativos Azul 5G e Turquesa QG em carvão ativado comercial. 83 f. 2008. Dissertação de Mestrado (Mestrado em Engenharia Química). PR, Toledo: Universidade Estadual do Oeste do Paraná - UNIOESTE, 2008.

SOTO, M. L.; MOURE, A.; DOMINGUES, H.; PARAJÓ, J. C. Recovery, concentration and purification of phenolic compounds by adsorption- A review. Journal of Foog Engineering, v. 105, n. 1, p. 1 - 27, 2011.

SUN, Y.; YUE, Q.; GAO, B.; LI, Q.; HUANG, L.; YAO, F.; XU, X. Preparation of activated carbon derived from cotton linter fibers by fused $\mathrm{NaOH}$ activation and its application for oxytetracycline (OTC) adsorption. Journal of Colloid and Interface Science, v. 368, p. 521-527, 2012.

TABORDA, I. P. Tratamento de águas contaminadas com crómio por adsorção em biossorventes catiónicos (cascas de crustáceos). 42f. 2009. Dissertação de Mestrado. Porto, Portugal: Universidade do Porto, 2009. 